\title{
Dental Anthropological Study of the Non-metric Traits of the Palauans
}

\author{
Hiroaki Ichikawa, and Masanobu Matsuno
}

Department of Anatomy and Physical Anthropology, Nihon University School of Dentistry at Matsudo, Matsudo, Chiba 271-8587, Japan

Correspondence to :

Hiroaki Ichikawa

E-mail : h_ichikawa@w8.dion.ne.jp

Keywords :

dental trait, Palauans, non-metric,

dental anthropology

\begin{abstract}
The frequency of the dental non-metric traits of school students in Koror, Palau was investigated. The parameters were recorded based on 22 crown traits classified by the Arizona State University Dental Anthropology System. In Palauans, the frequencies of shoveling and double shovel were not so high as in northeast Asians, but relatively high frequencies were found in tuberculum dentale in the maxillary second incisor and Cusp 5 in the maxillary first molar. Carabelli's trait and deflecting wrinkle were not found so frequently as in the Philippines and Bali populations. The frequency, 70.6\%, of the 4-cusp type of the mandibular second molar was highest in the Asian populations cited in this study. The principal coordinate plot for these 17 sets of scores, based on Smith's MMDs and standard deviations showed that data from Sundadont and Sinodont populations were differently positioned on the first axis. The Palauans belonged to Sundadont group and located in an extreme position on the right of the first axis and in relatively lower position in the second axis, which represented the unique combination of dental characters of Palauans.
\end{abstract}

\section{Introduction}

Republic of Palau is an island country in the western part of Micronesia (Fig. 1). Four major movements of human dispersals into Micronesia from surrounding islands since 3,600 years B.P. are proposed based on archaeological evidence (1). Various trials to trace the route of migration of peoples and to confirm the archaeological evidence have been made from the physical anthropological point of view. Skeletal analysis revealed that inhabitants in Micronesia were of mixed ancestry, while there is a discernible Melanesian contribution to some of the modern populations in Micronesia (2).

Palau was settled from further west, such as the Philippines or the island Indonesia on the lingual evidence (1), probably around 2,000 years ago. Palauan (also spelled Belauan) is the language spoken in Palau. It is a member of the Austronesian family of languages, and is considered to be one of two languages in Micronesia (the other being Chamorro) belonging to the Western Malayo -Polynesian group, all others considered to be mem- bers of either the Micronesian or Polynesian outlier subgroups of Eastern Malayo-Polynesian group (3).

The population of Palau is 20,303 at present, in which $70 \%$ are indigeneous people, but $30 \%$ are

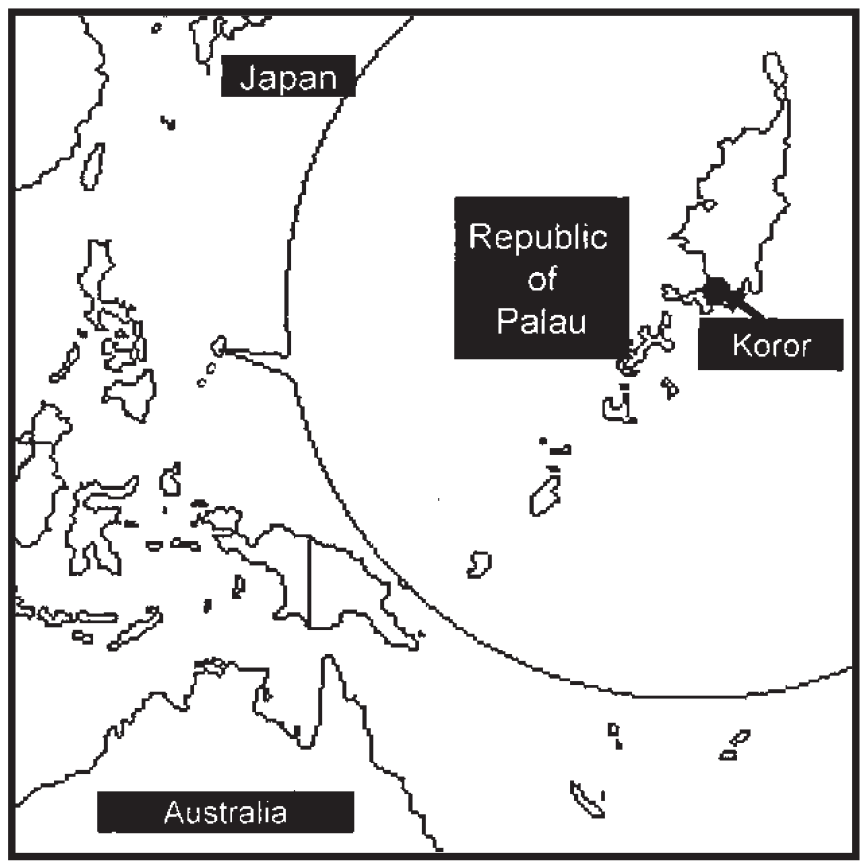

Fig. 1. The location of dental survey in Republic of Palau. 
people having Philippines or Japanese origin. Palau has been independent from USA since 1994. The capital locates in Melekeok, and its island area is 458 $\mathrm{km}^{2}$.

Turner (4) found that Micronesians, including prehistoric Guamanians, were dentally most similar to Borneo peoples, followed closely by samples from Fiji-Rotuma, Marquesas, Hawaii, and JavaSumatra. Several dental studies on the descriptions of dental crown and root traits in Micronesia have been reported $(5,6,7,8,9)$. These studies revealed the characteristics of dental traits of some populations in Micronesia, but more details of dental traits in Palau have not been reported, yet.

The purposes of this study were to describe the frequencies of dental non-metric characters in Palauans and to compare the results with other populations in Asia.

\section{Materials and Methods}

Dental plaster casts of the permanent dentition of 47 male and 47 female school students of Koror, the former capital of Republic of Palau, which were taken by Nihon University Dental Survey Team in 1996. Ages of the students were from 15 to 19 years old and dental traits were well preserved in this age range without severe attrition. Students having only indigenous parents and grand-parents were selected for examination. The parameters recorded in this study were 22 crown traits classified by the Arizona State University Dental Anthropology System (10). These are listed in Table 1 to Table 22, where the grades or scores for each trait are also shown. The data from males and females were pooled, because there were no significant differences (at the $5 \%$ level) between the sexes in the frequencies of all 22 traits observed in this study.

Scoring of the traits involved a four-point scale of none $(-)$, trace $( \pm)$, present $(+)$ and strong $(++)$, except for the following cases: interruption groove and winging in the upper incisor (6-point and 5-point scales respectively), odontome in the premolars (2point scale i.e. present or absent), lingual cusp variation in the lower molars and hypocone reduction in the upper molars (4 levels based on a combination of cusp numbers and their size), Carabelli's trait in the upper molars (5-point scale), and distal trigonid crest in the lower molars and cusp number in the lower molar (2-point scales).

In the comparison of frequencies in Palauans with those of 30 other East Asian populations, the number of crown parameters was reduced to 17 , and the number of levels in the various scales was reduced to two, with all points above $1(2-4,2-5,2-6)$ combined into one score (11). Thus the frequencies for each parameter were expressed simply as present or absent.

Using the frequencies of the 17 traits, Smith's Mean Measure of Divergence (MMD), together with the Freeman-Tukey method for inverse sine transformation, was used to determine inter-population distances, $(12,13,14)$. Affinity between Palauans and other Asian populations was expressed on two dimensions of the principal coordinate analysis based on Smith's MMD.

The statistical test, i.e., the MMD, the principal coordinate analysis, and the Chi-square test for sex differences, were all carried out on a personal computer using the JMP statistical package (SAS Institute Inc. ver. 6.0.0).

Table 1. Teeth and frequencies of shoveling in the Palau (sexes pooled).

\begin{tabular}{lrrrr} 
& \multicolumn{2}{c}{ UI1 } & \multicolumn{2}{c}{ UI2 } \\
Expression & $\mathrm{N}$ & \multicolumn{1}{c}{$\%$} & \multicolumn{1}{c}{$\mathrm{N}$} & \multicolumn{1}{c}{$\%$} \\
\hline$-:$ None & 18 & 19.15 & 27 & 30.00 \\
$\pm:$ Trace & 46 & 48.94 & 39 & 43.33 \\
$\quad+$ : Present & 29 & 30.85 & 24 & 26.67 \\
++ : Strong & 1 & 1.06 & 0 & 0.00 \\
Total & 94 & & 90 & \\
\hline
\end{tabular}

Table 2. Teeth and frequencies of double-shoveling in the Palau (sexes pooled).

\begin{tabular}{lrrrr} 
& \multicolumn{2}{c}{ UI1 } & \multicolumn{2}{c}{ UI2 } \\
Expression & \multicolumn{1}{c}{ N } & \multicolumn{1}{c}{ N } & \multicolumn{1}{c}{$\%$} \\
\hline$-:$ None & 55 & 58.51 & 55 & 59.78 \\
$\pm:$ Trace & 34 & 36.17 & 35 & 38.04 \\
+ : Present & 5 & 5.32 & 2 & 2.17 \\
++ : Strong & 0 & 0.00 & 0 & 0.00 \\
Total & 94 & & 92 & \\
\hline
\end{tabular}


Table 3. Teeth and frequencies of tuberculum dental in the Palau (sexes pooled).

\begin{tabular}{lrrrrrr} 
& \multicolumn{2}{c}{ UI1 } & \multicolumn{2}{c}{ UI2 } & \multicolumn{2}{c}{ UC } \\
Expression & $\mathrm{N}$ & $\%$ & $\mathrm{~N}$ & $\%$ & \multicolumn{1}{c}{$\mathrm{N}$} & $\%$ \\
\hline- : None & 26 & 27.96 & 56 & 61.54 & 19 & 21.35 \\
\pm : Trace & 33 & 35.48 & 13 & 14.29 & 34 & 38.20 \\
+ + : Present & 31 & 33.33 & 18 & 19.78 & 32 & 35.96 \\
++ : Strong & 3 & 3.23 & 4 & 4.40 & 4 & 4.49 \\
Total & 93 & & 91 & & 89 &
\end{tabular}

Table 4. Teeth and frequencies of spinal process in the Palau (sexes pooled).

\begin{tabular}{lrrrr} 
& \multicolumn{2}{c}{ UI1 } & \multicolumn{2}{c}{ UI2 } \\
Expression & $\mathrm{N}$ & $\%$ & \multicolumn{1}{c}{$\mathrm{N}$} & \multicolumn{1}{c}{$\%$} \\
\hline$-:$ None & 50 & 54.95 & 83 & 93.26 \\
$\pm:$ Trace & 24 & 26.37 & 3 & 3.37 \\
+ : Present & 16 & 17.58 & 2 & 2.25 \\
++ : Strong & 1 & 1.10 & 1 & 1.12 \\
Total & 91 & & 89 & \\
\hline
\end{tabular}

Table 5. Teeth and frequencies of interruption groove in the Palau (sexes pooled).

\begin{tabular}{lrrrr} 
& \multicolumn{2}{c}{ UI1 } & \multicolumn{2}{c}{ UI2 } \\
Expression & $\mathrm{N}$ & $\%$ & $\mathrm{~N}$ & $\%$ \\
\hline- : None & 93 & 100 & 81 & 90.00 \\
MB : Mesiolingual border & 0 & 0.00 & 2 & 2.22 \\
DB : Distlingual border & 0 & 0.00 & 5 & 5.56 \\
MD : Mesio and distlingual border & 0 & 0.00 & 0 & 0.00 \\
MA : Mesial area & 0 & 0.00 & 2 & 2.22 \\
DA : Distal area & 0 & 0.00 & 0 & 0.00 \\
Total & 93 & & 90 & \\
\hline
\end{tabular}

Table 6. Teeth and frequencies of winging in the Palau (sexes pooled).

\begin{tabular}{lrr} 
& \multicolumn{2}{c}{ UI1 } \\
Expression & $\mathrm{N}$ & \multicolumn{1}{c}{$\%$} \\
\hline $\mathrm{C}+:$ Present (counter winging) & 9 & 9.57 \\
$\mathrm{C} \pm:$ Trace (counter winging) & 19 & 20.21 \\
$\quad-:$ None & 52 & 55.32 \\
$\pm:$ Trace & 6 & 6.38 \\
$\quad+:$ Present & 8 & 8.51 \\
Total & 94 & \\
\hline
\end{tabular}

Table 7. Teeth and frequencies of canine mesial ridge in the Palau (sexes pooled).

\begin{tabular}{lrr} 
& \multicolumn{2}{c}{$\mathrm{UC}$} \\
Expression & $\mathrm{N}$ & $\%$ \\
\hline$-:$ None & 78 & 88.64 \\
$\pm:$ Trace & 7 & 7.95 \\
$+:$ Present & 3 & 3.41 \\
++ : Strong & 0 & 0.00 \\
Total & 88 & \\
\hline
\end{tabular}

Table 8. Teeth and frequencies of canine distal accessory ridge in the Palau (sexes pooled).

\begin{tabular}{lrr} 
& \multicolumn{3}{c}{$\mathrm{UC}$} \\
Expression & $\mathrm{N}$ & $\%$ \\
\hline$-:$ None & 46 & 53.49 \\
$\pm:$ Trace & 25 & 29.07 \\
+ : Present & 14 & 16.28 \\
$++:$ Strong & 1 & 1.16 \\
Total & 86 & \\
\hline
\end{tabular}

Table 9. Teeth and frequencies of accessory marginal tubercle in the Palau (sexes pooled).

\begin{tabular}{lrrrr} 
& \multicolumn{2}{c}{ UP1 } & \multicolumn{2}{c}{ UP2 } \\
Expression & $\mathrm{N}$ & $\%$ & \multicolumn{1}{c}{$\mathrm{N}$} & \multicolumn{1}{c}{$\%$} \\
\hline$-:$ None & 74 & 79.57 & 75 & 81.52 \\
$\pm:$ Trace & 12 & 12.90 & 12 & 13.04 \\
$\quad+:$ Present & 6 & 6.45 & 5 & 5.43 \\
++ : Strong & 1 & 1.08 & 0 & 0.00 \\
Total & 93 & & 92 & \\
\hline
\end{tabular}

Table 10. Teeth and frequencies of odontomes in the Palau (sexes pooled).

\begin{tabular}{lrrrrrrrr} 
& \multicolumn{2}{c}{ UP1 } & \multicolumn{2}{c}{ UP2 } & \multicolumn{2}{c}{ LP1 } & \multicolumn{2}{c}{ LP2 } \\
Expression & $\mathrm{N}$ & $\%$ & $\mathrm{~N}$ & $\%$ & $\mathrm{~N}$ & $\%$ & $\mathrm{~N}$ & $\%$ \\
\hline$-:$ None & 90 & 100 & 86 & 100 & 93 & 100 & 92 & 100 \\
+ : Present & 0 & 0.00 & 0 & 0.00 & 0 & 0.00 & 0 & 0.00 \\
Total & 90 & & 86 & & 93 & & 92 & \\
\hline
\end{tabular}

Table 11. Teeth and frequencies of lingual cusp variation in the Palau (sexes pooled).

\begin{tabular}{lrrrr} 
& \multicolumn{2}{c}{ LP1 } & \multicolumn{2}{c}{ LP2 } \\
Expression & $\mathrm{N}$ & $\%$ & \multicolumn{1}{c}{$\mathrm{N}$} & \multicolumn{1}{c}{$\%$} \\
\hline 0: None & 3 & 3.37 & 0 & 0.00 \\
1: One lingual cusp & 68 & 76.40 & 29 & 31.52 \\
2: Two lingual cusp & 15 & 16.85 & 61 & 66.30 \\
3: Three lingual cusp & 3 & 3.37 & 2 & 2.17 \\
Total & 89 & & 92 & \\
\hline
\end{tabular}


Table 12. Teeth and frequencies of hypocone reduction in the Palau (sexes pooled).

\begin{tabular}{lrrrr}
\multirow{2}{*}{ Expression } & \multicolumn{2}{c}{ UM1 } & UM2 \\
\hline $4+:$ Large cusp & 81 & 95.29 & 1 & 1.35 \\
$4-:$ Small cusp & 3 & 3.53 & 50 & 67.57 \\
$3+:$ Faint cusp & 1 & 1.18 & 19 & 25.68 \\
$3-:$ None or faint ridge & 0 & 0.00 & 4 & 5.41 \\
Total & 85 & & 74 & \\
\hline
\end{tabular}

Table 13. Teeth and frequencies of metacone reduction in the Palau (sexes pooled).

\begin{tabular}{crrrr} 
& \multicolumn{2}{c}{ UM1 } & \multicolumn{2}{c}{ UM2 } \\
Expression & $\mathrm{N}$ & $\%$ & \multicolumn{1}{c}{ N } & $\%$ \\
\hline- : None & 65 & 77.38 & 8 & 11.11 \\
\pm : Trace & 19 & 22.62 & 40 & 55.56 \\
+ : Present & 0 & 0.00 & 23 & 31.94 \\
++ : Strong & 0 & 0.00 & 1 & 1.39 \\
Total & 84 & & 72 & \\
\hline
\end{tabular}

Table 14. Teeth and frequencies of cusp 5 in the Palau (sexes pooled).

\begin{tabular}{crrrr} 
& \multicolumn{2}{c}{ UM1 } & \multicolumn{2}{c}{ UM2 } \\
Expression & $\mathrm{N}$ & $\%$ & $\mathrm{~N}$ & $\%$ \\
\hline- : None & 39 & 50.00 & 46 & 68.66 \\
\pm : Trace & 17 & 21.79 & 11 & 16.42 \\
+ : Present & 20 & 25.64 & 9 & 13.43 \\
++ : Strong & 2 & 2.56 & 1 & 1.49 \\
Total & 78 & & 67 & \\
\hline
\end{tabular}

Table 15. Teeth and frequencies of Carabelli's trait in the Palau (sexes pooled).

\begin{tabular}{lrrrr} 
& \multicolumn{2}{c}{ UM1 } & UM2 \\
Expression & $\mathrm{N}$ & $\%$ & $\mathrm{~N}$ & \multicolumn{1}{c}{$\%$} \\
\hline$-:$ None & 42 & 46.67 & 72 & 91.14 \\
$\pm:$ Line & 19 & 21.11 & 4 & 5.06 \\
$\pm:$ Trace & 15 & 16.67 & 2 & 2.53 \\
+ : Tubercle & 12 & 13.33 & 1 & 1.27 \\
++ : Cusp & 2 & 2.22 & 0 & 0.00 \\
Total & 90 & & & \\
\end{tabular}

Table 16. Teeth and frequencies of protostylid in the Palau (sexes pooled).

\begin{tabular}{lrrrr} 
& \multicolumn{2}{c}{ LM1 } & \multicolumn{2}{c}{ LM2 } \\
Expression & $\mathrm{N}$ & $\%$ & $\mathrm{~N}$ & \multicolumn{1}{c}{$\%$} \\
\hline$-:$ None & 65 & 79.27 & 78 & 91.76 \\
$\pm:$ Trace & 15 & 18.29 & 6 & 7.06 \\
+ : Tubercle & 2 & 2.44 & 1 & 1.18 \\
++ : Cusp & 0 & 0.00 & 0 & 0.00 \\
Total & 82 & & 85 & \\
\hline
\end{tabular}

Table 17. Teeth and frequencies of deflecting wrinkle in the Palau (sexes pooled).

\begin{tabular}{crrrr} 
& \multicolumn{2}{c}{ LM1 } & \multicolumn{2}{c}{ LM2 } \\
Expression & $\mathrm{N}$ & $\%$ & $\mathrm{~N}$ & $\%$ \\
\hline$-:$ None & 35 & 49.30 & 82 & 100 \\
$\pm:$ Trace & 23 & 32.39 & 0 & 0.00 \\
+ : Present & 12 & 16.90 & 0 & 0.00 \\
++ : Strong & 1 & 1.41 & 0 & 0.00 \\
Total & 71 & & 82 & \\
\hline
\end{tabular}

Table 18. Teeth and frequencies of distal trigonid crest in the Palau (sexes pooled).

\begin{tabular}{lrrrr} 
& \multicolumn{2}{c}{ LM1 } & \multicolumn{2}{c}{ LM2 } \\
Expression & N & $\%$ & N & $\%$ \\
\hline$-:$ Abcent & 73 & 100 & 78 & 100 \\
+ : Present & 0 & 0.00 & 0 & 0.00 \\
Total & 73 & & 78 & \\
\hline
\end{tabular}

Table 19. Teeth and frequencies of cusp 6 in the Palau (sexes pooled).

\begin{tabular}{lrrrr} 
& \multicolumn{2}{c}{ LM1 } & \multicolumn{2}{c}{ LM2 } \\
Expression & $\mathrm{N}$ & $\%$ & $\mathrm{~N}$ & \multicolumn{1}{c}{$\%$} \\
\hline$-:$ None & 67 & 78.82 & 71 & 85.54 \\
$\pm:$ C5 $>$ C6 & 14 & 16.47 & 4 & 4.82 \\
+ + C5 $=$ C6 & 4 & 4.71 & 6 & 7.23 \\
$++:$ C5 $<$ C6 & 0 & 0.00 & 2 & 2.41 \\
Total & 85 & & 83 & \\
\hline
\end{tabular}

Table 20. Teeth and frequencies of cusp 7 in the Palau (sexes pooled).

\begin{tabular}{lrrrr} 
& \multicolumn{2}{c}{ LM1 } & \multicolumn{2}{c}{ LM2 } \\
Expression & $\mathrm{N}$ & $\%$ & $\mathrm{~N}$ & $\%$ \\
\hline$-:$ None & 89 & 98.89 & 87 & 100 \\
$\pm:$ Faint cusp & 0 & 0.00 & 0 & 0.00 \\
+ : Small cusp & 1 & 1.11 & 0 & 0.00 \\
++ : Large cusp & 0 & 0.00 & 0 & 0.00 \\
Total & 90 & & 87 & \\
\hline
\end{tabular}

Table 21. Teeth and frequencies of groove pattern in the Palau (sexes pooled).

\begin{tabular}{lrrrr} 
& \multicolumn{2}{c}{ LM1 } & \multicolumn{2}{c}{ LM2 } \\
Expression & \multicolumn{1}{c}{$\mathrm{N}$} & \multicolumn{1}{c}{$\%$} & \multicolumn{1}{c}{$\mathrm{N}$} & \multicolumn{1}{c}{$\%$} \\
\hline Y pattern & 56 & 87.50 & 2 & 2.94 \\
+ pattern & 6 & 9.38 & 47 & 69.12 \\
X pattern & 2 & 3.13 & 19 & 27.94 \\
Total & 64 & & 68 & \\
\hline
\end{tabular}


Table 22. Teeth and frequencies of cusp number in the Palau (sexes pooled).

\begin{tabular}{lrrrc} 
& \multicolumn{2}{c}{ LM1 } & \multicolumn{2}{c}{ LM2 } \\
Expression & \multicolumn{1}{c}{ N } & \multicolumn{1}{c}{$\%$} & N & $\%$ \\
\hline $4: 4$ cusp & 4 & 6.25 & 48 & 70.59 \\
$5: 5$ cusp & 60 & 93.75 & 20 & 29.41 \\
Total & 64 & & 68 & \\
\hline
\end{tabular}

\section{Results}

The frequencies of the 22 non-metric traits of the upper and lower dentition in Palauans are shown in different grades of expression in Table 1 to Table 22 . They are expressed by the individual count and percentage. Total sample numbers are different from trait to trait because of differences in the number of observable cases. Table 23 shows the dichotomized frequencies of the 17 analyzed traits in Palauans to compare with those of other Asian populations cited from anthropological or dental science journals.

In Palauans, the frequencies of shoveling and double shovel are not so high as in northeast Asians, but relatively high frequencies were found in tuberculum dentale in the maxillary second incisor and Cusp 5 in the maxillary first molar. Carabelli's trait and deflecting wrinkle were not found so frequently as in the Philippines and Bali populations. The frequency,
$70.59 \%$, of the 4-cusp type of the mandibular second molar was highest in the Asian populations cited in this study.

Table 24 shows the dichotomized frequencies of the 17 traits in 30 populations of East Asia, and also in the Palauans. Frequencies for the populations other than the Palauans were taken from already published studies $\left(11,15^{-26}\right)$. The traits which showed a relatively low frequency in the Palauans compared with other Asian populations were shoveling and double shoveling of the upper central incisor, the Carabelli's trait in the upper first molar, and deflecting wrinkle, distal trigonid crest, cusp 6, cusp 7 , and Y-groove pattern in the lower first molar. On the other hand, traits with a relatively high frequency were tuberculum dentale in upper second incisor, mesial ridge in upper canine, cusp 5 in upper first molar and Cusp number in lower second molar.

The principal coordinate plot for these 17 sets of scores, based on Smith's MMDs and standard deviations, is shown in Fig. 2. Data from Sundadont and Sinodont populations were differently positioned on the first axis. The Palauans belonged to Sundadont group and located in an extreme position on the right of the first axis and in relatively lower position in the second axis.

Table 23. Dichotomized frequency of 17 selected traits in the Palau

\begin{tabular}{lllr}
\hline \multicolumn{1}{c}{ Trait } & \multicolumn{1}{c}{ Tooth } & \multicolumn{1}{c}{ Expression dichotomy* } & Frequency in Palau $(\%)$ \\
\hline Shoveling & UI1 & $(++,+) /(++\sim-)$ & 31.91 \\
Double-shoveling & UI1 & $(++,+) /(++\sim-)$ & 5.32 \\
Tuberculum dentale & UI2 & $(++\sim \pm) /(++\sim-)$ & 38.46 \\
Mesial ridge & UC & $(++\sim \pm) /(++\sim-)$ & 11.36 \\
Distal accessory ridge & UC & $(++\sim \pm) /(++\sim-)$ & 46.51 \\
Lingual cusp variation & LP2 & $(3,2) /(3 \sim 0)$ & 68.48 \\
Odontomes & U-L, P1-2 & $(+) /(+,-)$ & 0.00 \\
Hypocone & UM2 & $(4+\sim 3+) /(4+\sim 3-)$ & 94.59 \\
Cusp 5 & UM1 & $(++\sim \pm) /(++\sim-)$ & 50.00 \\
Carabelli's trait & UM1 & $(++,+) /(++\sim-)$ & 15.56 \\
Protostylid & LM1 & $(++\sim \pm) /(++\sim-)$ & 20.73 \\
Deflecting wrinkle & LM1 & $(++) /(++\sim-)$ & 1.41 \\
Distal trigonid crest & LM1 & $(+) /(+,-)$ & 0.00 \\
Cusp 6 & LM1 & $(++\sim \pm) /(++\sim-)$ & 21.18 \\
Cusp 7 & LM1 & $(++\sim \pm) /(++\sim-)$ & 1.11 \\
Y groove pattern & LM2 & $(\mathrm{Y}) /(\mathrm{Y},+, \mathrm{X})$ & 2.94 \\
Cusp number & LM2 & $(4) /(5,4)$ & 70.59 \\
\hline
\end{tabular}

* : (Present range of grades)/(total range of grades) 


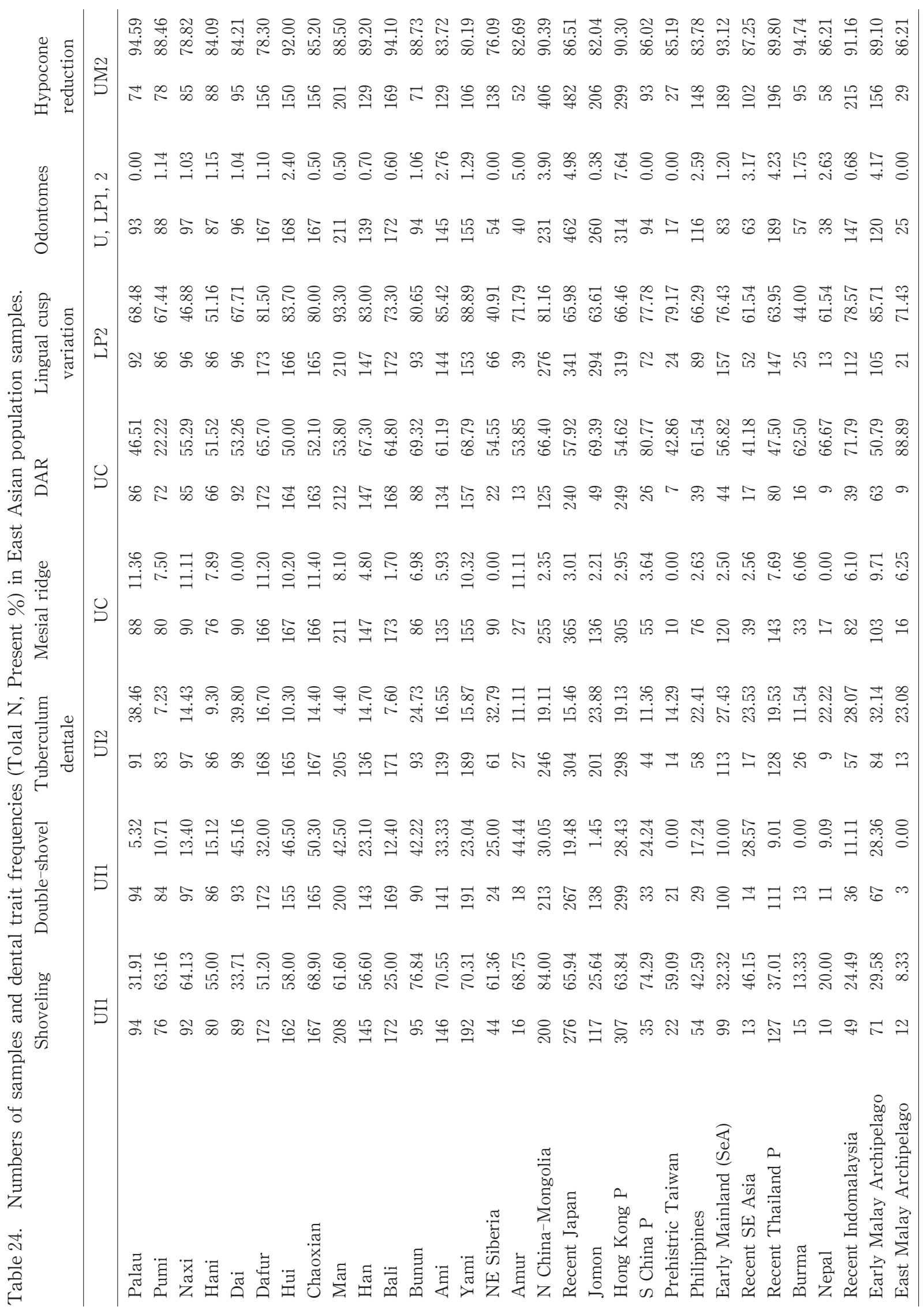




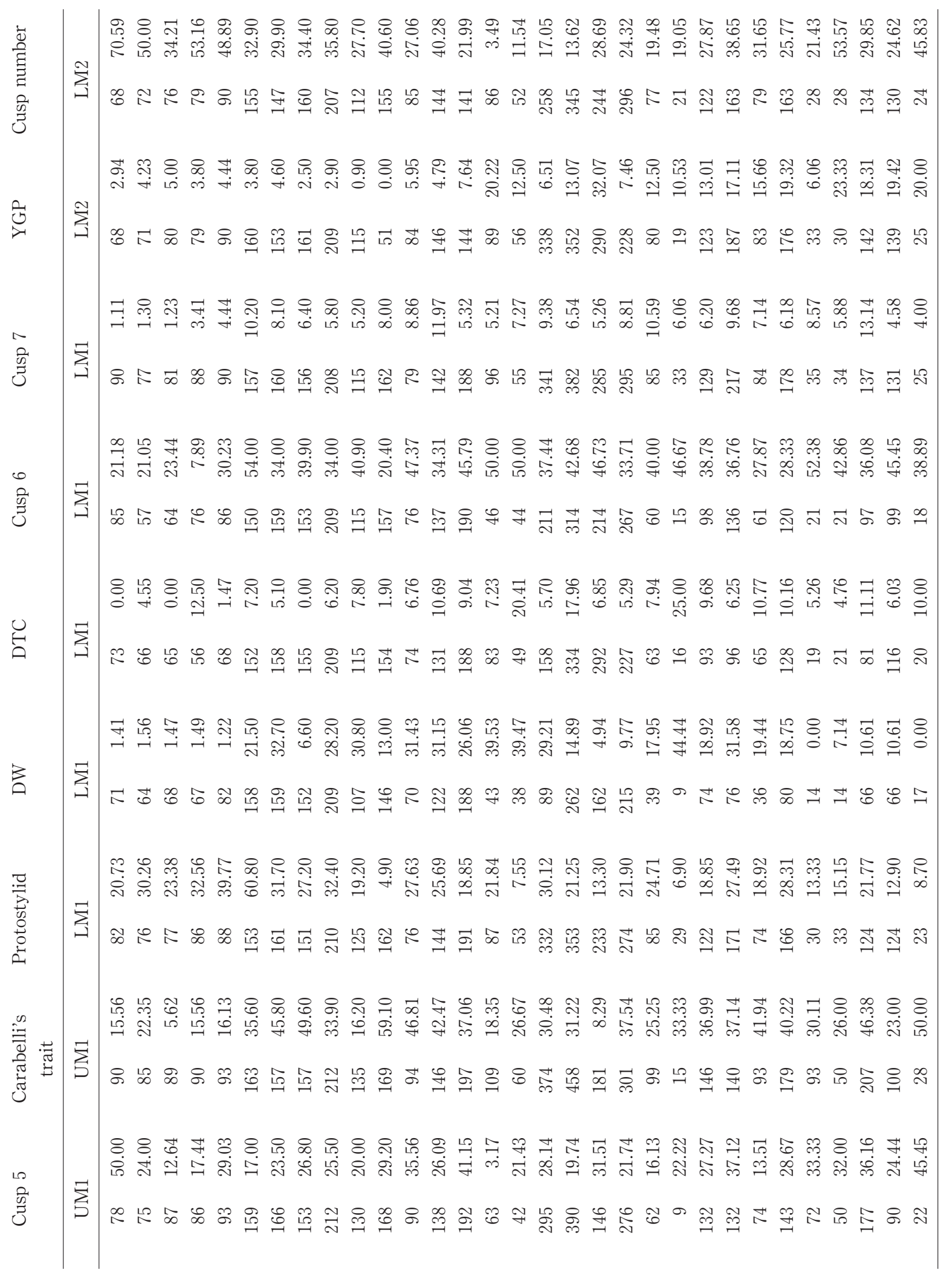




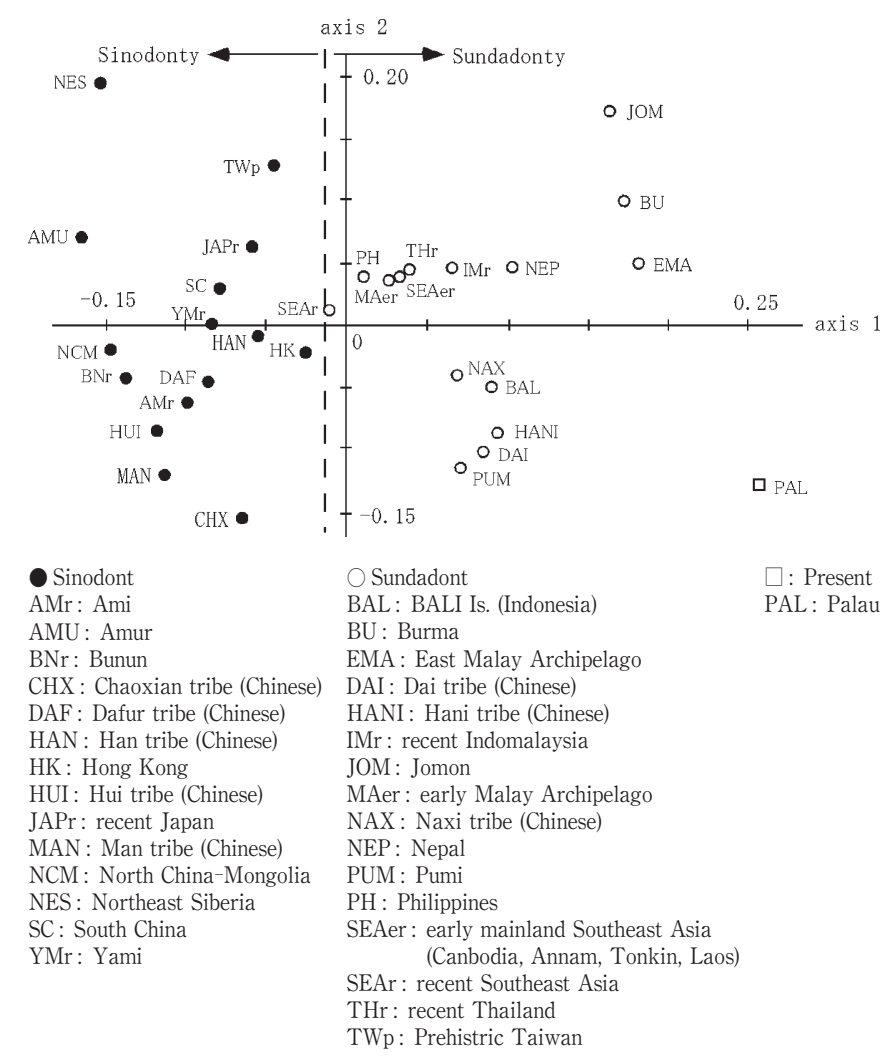

Fig. 2. Two dimensional expression of multidimensional scaling applied to Smith's MMD based on 17 crown traits in 31 Asian populations. Proportion of variation explained by axis 1 and 2 is $36.7 \%$ and $20.2 \%$, respectively.

\section{Discussion}

There are two major dental and morphological variations among Mongoloid populations, which are called Sinodonty and Sundadonty (4). These are categorical definitions of the combined dental characteristics of the Northeast and Southeast Asian populations, respectively. In addition, Sunda-Pacific and Sahul-Pacific type of the dentition has been also proposed to represent the dentition of Polynesians and Micronesians in Sunda-Pacific, and Melanesians in Sahul-Pacific (10).

Thirty East Asian populations compared with Palauans in this study were 16 Sinodont and 14 Sundadont populations (6, 7, 8, 15-22). The Northeast and Southeast Asian populations corresponded to Sinodont and Sundadont in Turner's classification were separated out in negative and positive directions on the first principal coordinate of the principal coordinate analysis, as can be seen in Fig. 2. A multiple regression analysis demonstrated that the first principal coordinate correlated positively with LM2 cusp number and negatively with UI1 shoveling, UI1 double-shoveling and LM1 deflecting wrinkle. The second principal coordinate correlated positively with LM2 groove pattern and negatively with LM2 cusp number (data not shown).

As in the Turner's classification, dental characters in Micronesians and Polynesians are similar. For example, Hanihara (27) presented close affinity between Micronesians including Ponape, Guam and Tinian, and Polynesians based on the nine discrete crown traits. He also presented a clustering of Oceanic populations including Micronesians based on mesiodistal diameter of the tooth from skeletal materials, and discussed that Ponape in Central Micronesia was clustered in the group of Polynesians, but Guam and Tinian were independently clustered together separated from Polynesians, although sample size was small (28).

Sakurada (1999) also studied 6 non-metric traits of two Micronesians, and compared their frequencies with other Pacific peoples (29). His study revealed that Micronesians dental traits were similar to those in Polynesians, but different from Melanesians. However, the traits observed were not sufficient and the populations compared were limited to Pacific peoples in his study. In our data, although other Pacific peoples were not included, many of Asians were included. The isolated position of Palau among many Asians suggests that dental traits of Palauans are consisted of specific combination of the frequency. It was suggested that other Pacific peoples may occupy the positions around Palau if they are analyzed in the future.

In the study of tooth size of Pacific populations based on mesiodistal and buccolingual diameter, Palauans were grouped with Samoans and modern Philippines (30). This result was thought to be reasonable from the view point of migration history of Palauans (1). However, it was difficult to find the relationship between Palau and Philippine from our data.

Although no data are available for the comparison of 22 traits of the dentition in Pacific peoples, the 
position of Palauans in Fig. 2 in this study might represent the specific dental traits of the Pacific people. The position of Palauans was in the Sundadont group, but far from Philippines and other Southeast populations. More data of Pacific peoples are needed to detect affinities with other Asian populations.

\section{Conclusion}

In Palauans, the frequencies of shoveling and double shovel are not so high as in northeast Asians, but relatively high frequencies were found in tuberculum dentale in the maxillary second incisor and Cusp 5 in the maxillary first molar. Carabelli's trait and deflecting wrinkle were not found so frequently as in the Chinese or Taiwanese populations. The frequency, $70.59 \%$, of the 4 -cusp type of the mandibular second molar was highest in the Asian populations cited in this study.

The principal coordinate plot for these 17 sets of scores, based on Smith's MMDs and standard deviations showed that data from Sundadont and Sinodont populations were differently positioned on the first axis. The Palauans belonged to Sundadont group and located in an extreme position on the right of the first axis and in relatively lower position in the second axis, which represented the unique combination of dental characters of Palauans.

\section{Acknowledgment}

We are grateful to Professor Eisaku Kanazawa, Department of Anatomy and Physical Anthropology, Nihon University School of Dentistry at Matsudo, for his advice on the conduct of this research and reading the manuscript. Thanks also to Drs. Kayoko Sasaki and Yuriko Igarashi, Department of Anatomy and Physical Anthropology, Nihon University School of Dentistry at Matsudo, for their assistance in the measurement of teeth and the statistical analysis, and to Professor Emeritus John T. Mayhall for his brushing up of the text and kind revision of the manuscript. A part of this study was supported by the Grant-in- aid for Scientific Research from Japan Society for the Promotion of Science, no. 17570197.

\section{References}

1. Intoh M. : Human dispersals into Micronesia. Anthropological Science, 105: 15-28, 1997.

2. Turner CG II: Major features of Sundadonty and Sinodonty, including suggestions about East Asian microevolution, population history, and Pleistocene relationships with Australian aboriginals. Amer J Phys Anthrop, 82 : 295-317, 1990.

3. Howells WW: The Pacific Islanders. Charles Scribner's Sons. New York. 1973.

4. Shutler RJr, Marck JC: On the dispersal of the Austronesian horticulturalists, Arch Phys Anthropol Ocean, 10: 81-113, 1975.

5. Leigh RW : Dental Morphology and pathology of prehistoric Guam. Memoirs of the Bernice P. Bishop Museum, 11: 451-479, 1929.

6. Harris EF, Turner CGII, Underwood JH : Dental morphology of living Yap islanders, Micronesia, Arch Phys Anthropol Ocean, 10: 218-234, 1975.

7. Sakai T, Kawamoto, K, Tomiyasu, S: Dental morphologies of Micronesians. J Anthropol Soc Nippon, 93: 337-358, 1985.

8. Sakuma M, Mine K, Roberts T, Kumagai M, Polloi $\mathrm{AH}$ : The rotation of the maxillary central incisors among inhabitants in the Republic of Palau. "The prompt report of the fifth scientific survey of the South Pacific," Research Center for the South Pacific, Kagoshima University, 71-75, 1987.

9. Mine K, Sakuma M, Figir MB, Gajdusek JT, Gufsag $\mathrm{S}$ : Shovel-shaped incisors of the inhabitants in the state of Yap, the Federated States of Micronesia. "The prompt report of the fifth scientific survey of the South Pacific," Research Center for the South Pacific, Kagoshima University, 76-79, 1987.

10. Turner CG II, Nichol CR, Scott GR: Scoring Procedures for Key Morphological Traits of the Permanent Dentition: The Arizona State University Dental Anthropology System, in Advances in Dental Anthropology, Wiley-Liss, New York, 1991, 13-31.

11. Turner CG II : Late Pleistocene and Holocene population history of East Asia based on dental variation, Am J Phys Anthropol, 73 : 305-321, 1987.

12. Berry AC, Berry RJ : Epigenetic variation in the human cranium. J Anat, 101: 361-379, 1967.

13. Freeman MF, Tukey JW : Transformations related to the angular and square root, Ann Math Stat, 21: 607 $-611,1950$.

14. Green RF, Suchey JM : The use of inverse sine transformations in the analysis of non-metric cranial data, Am J Phys Anthrop, 45: 61-68, 1976.

15. Manabe Y, Ito R, Kitagawa Y, Oyamada J, Rokutanda A, Nagamoto S, Kobayashi S, Kato K: Non-metric tooth crown traits of the Thai, Aka and Yao tribes of Northern Thailand. Archs oral Biol 42 : 283-291, 1997. 
16. Manabe Y, Rokutanda A, Kitagawa Y: Nonmetric Tooth crown traits in the Ami tribe, Taiwan Aborigines: Comparisons with other East Asian populations. Hum Biol, 64 : 717-726, 1992.

17. Manabe Y, Rokutanda A, Kitagawa Y, Oyamada J : Genealogical position of native Taiwanese (Bunun tribe) in East Asian populations based on tooth crown morphology, J Anthropol Soc Nippon, 99: 33-47, 1991.

18. Kanazawa E, Shirono Y, Nakayama M, Yamada H, Hanamura H, Kondo S: Distribution of tubercleshaped incisors in South Pacific populations, Anthropological Science 109: 225-238, 2001.

19. Kobayashi K, Matsuno M: Dental Anthropological Study of Non-metric Traits in the Hani Nationality of Chinese Minorities. Intnl J Oral-Med Sci, 4: 61-70, 2005.

20. Beppu K : Dental Characteristics in the Naxi Tribe of Yunnan, China: Comparative Analysis between Naxi and East Asian Populations. J Kyushu Dent Soc, 57 : 191-196, 2003. (in Japanese)

21. Chikushi S: Dental Characteristics in the Dafurs Tribe of Inner Mongolia, China. J Kyushu Dent Soc, 55 : 189-205, 2001. (in Japanese)

22. Fukunari F: Dental Characteristics in the Manchu Tribe of Xin-Bin, China. J Kyushu Dent Soc, 53: 6388, 2003. (in Japanese)

23. Jin $\mathrm{H}$ : Dental Characteristics in the Chaoxian of Liao
-Ning Province, China. J Kyushu Dent Soc, 53 : 529537, 2003. (in Japanese)

24. Kikuti N : Dental Characteristics in the Han of LiaoNing, China. J Kyushu Dent Soc, 51 : 193-216, 2003. (in Japanese)

25. Kiyosue T: Dental Characteristics in the Hui of Liao -Ning, China. J Kyushu Dent Soc, 54 : 510-520, 2000. (in Japanese)

26. Yamaguchi Y : Dental Characteristics in Balinese. J Kyushu Dent Soc, 50 : 663-680, 1996. (in Japanese)

27. Hanihara T: Negritos, Australian Aborigines, and the "Proto-Sundadont" Dental Pattern: The Basic Population in East Asia, V. Am J Phys Anthrop, 88 : 183-196, 1992.

28. Hanihara T: Biological Relationships among Southeast Asians, Jomonese, and the Pacific Populations as Viewed from Dental Characters: The Basic Populations in East Asia, X. J Anthrop Soc Nippon, 100 : 53 $-68,1992$.

29. Sakurada H : Frequency of Non-metrical Dental Traits in Two Micronesian Populations. Nihon Univ J Oral Sci, 25: 7-14, 1999.

30. Kanazawa E, Matsuno M, Nakabayashi T, Igarashi Y, Nagai, A : Tooth size of living peoples in Western and Eastern Micronesian populations, Anthrop Sci 106 : 199-208, 1998. 